\title{
Discussion on Agricultural Cleaner Production
}

\author{
An Wang ${ }^{1,}$, Miaomiao $\mathrm{Li}^{2, \mathrm{~b}}$ \\ ${ }^{1}$ Education School, Jiangxi Science \& Technology Normal University, Nanchang, China \\ 2 Jiangxi Science \& Technology Normal University, Nanchang, China \\ awanganwangmenghua@163.com, blimiaom8899@163.com
}

Keywords: agriculture, cleaner production, pollution, measure.

\begin{abstract}
On the basis of the concept, contents and goals of the agricultural cleaner production in China, four major environmental problems in agricultural development and the problems of agricultural cleaner production in our country was pointed out, moreover, the necessity and the measures of developing agricultural cleaner production verification were put forward.
\end{abstract}

\section{Introduction}

Agricultural production is the inevitable choice for the sustainable development of agriculture in China, and is an important carrier of solving the environment pollution from the source and the process. China is a large agricultural country, so accelerating the development of agricultural production is an important and urgent task.

\section{The connotation of agricultural cleaner production}

Agricultural cleaner production refers to the practical production technology which can meet the need of agricultural production, make full use of resources rationally, and protect the environment. In essence, it mainly improves agricultural production technology, reduces agricultural pollution and its risk to human being and the environment through producing and using environment-friendly "green" agricultural chemicals (fertilizers, pesticides, plastic, film and so on). It does not rule out the agricultural chemicals completely, but considers the ecological safety of these agricultural chemicals in use, to realize the continuous unity of social, economic and ecological benefit, and promote the sustainable development of agriculture.

It contains three main contents. First, clean input. Such as clean raw materials, agricultural equipment and energy, especially clean energy (including the clean use, energy saving technology and energy efficiency); second, clean output. It mainly refers to clean agricultural products which are not harm to human health and ecological environment in the process of consumption; third, clean production process. Adopt clean production procedures, technology and management, use less chemical agricultural activities as far as possible, to ensure the agricultural production $t$ nutritional, harmless and non-toxic.

\section{The necessity of agricultural cleaner production}

\subsection{Blind use of pesticides and fertilizers.}

The amount of pesticide and fertilizer has grown rapidly all the time (the exact number is shown in figure 1 and 2). In the process of agricultural production, excessive unbalanced fertilizer, on one hand, may reduce the quality of agricultural products and increase difficulty of product export, on the other hand, may damage the agricultural ecological environment seriously. In farmland ecological system, the leaching and runoff losses of nitrogen fertilizer reach about 2 million ton each year. The loss of a large number of chemical fertilizers causes serious pollution to the environment, mainly to the water, the air and the soil. The irrational use of pesticides , on one hand, may cause the waste of resources, ecological destruction and environmental pollution, on the other hand, may cause the pesticide 
residues in agricultural products exceed the standard to endanger human and animal health and safety.

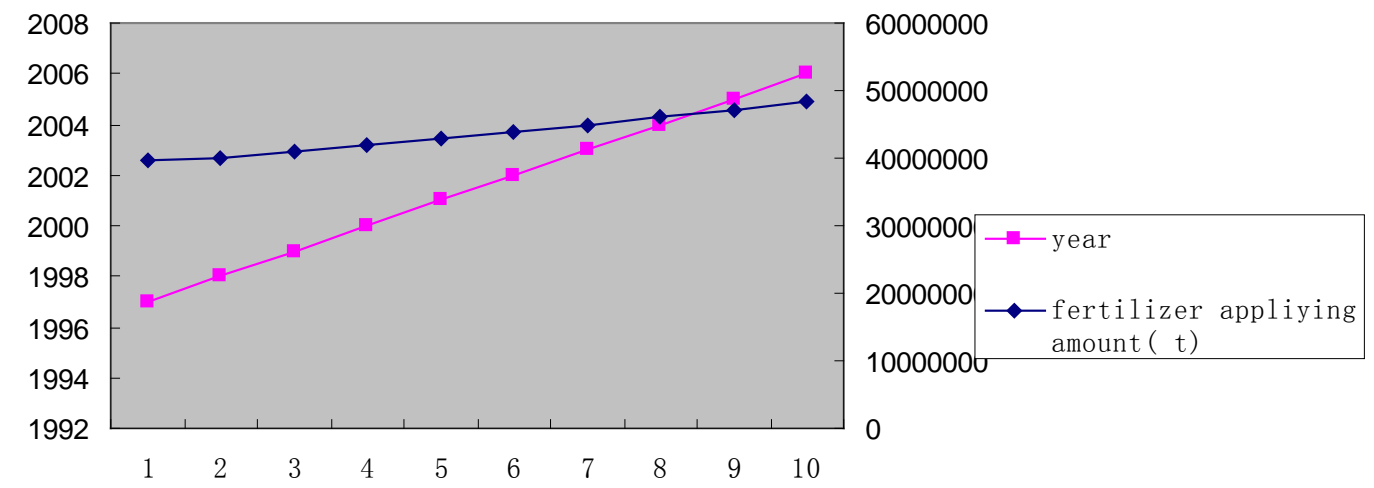

Figure1. The chart of fertilizer applying amount in China duing 1997-2006

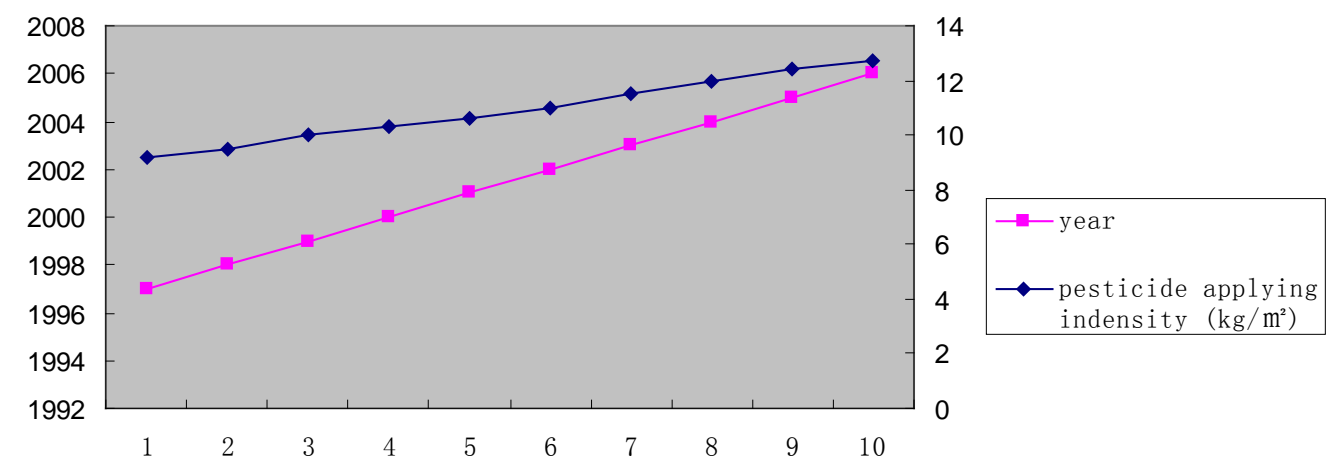

Figure2. The chart of pesticide applying average in China duing 1997-2006

\subsection{Plastic pollution.}

The annual production of agricultural film reaches 1 million tons, and is even increasing at annual rate of $10 \%$. With the increasing amount, the using area is also extending in large amplitude and has exceeded 100 million mu. No matter what kind of crop films and ultrathin film cover, all have residual film. According to statistics, the annual plastic sheeting residues is up to 350000 ton, at $42 \%$ rate. That is to say, nearly half of the plastic film residues are left in soil. Mulch accumulated in soil affects the permeability and the soil and the growth of crop root, which leads to crop failures and white pollution in degree, and destructs the ecological environment.

\subsection{Straw burning pollution.}

In summer and autumn every year in rural areas, a large number of straws is piled in the field and can not be handle properly and timely. According to the survey, about $70 \%$ wheat straws are burned onsite while less than $20 \%$ are used as industrial raw materials and energy fuel. Burning straw not only causes atmospheric pollution, but also reduces the fertility of the soil, and the abandoned straw in the field also causes certain environment pollution.

\section{The problems existing in agricultural cleaner production}

\subsection{The policy and system is not perfect.}

The current laws and regulations in China to control agricultural pollution are not perfect. Environmental compensation won't be paid for the pollution brought in the production. Under the background, the agricultural enterprises are rarely willing to increase investment in pollution control. This kind of "market failure" is caused by the unreasonable environment pollution control system and resource pricing system, and ultimately makes the demand of clean production technology lack motivation. 


\subsection{The technology and talents are deficient.}

Clean production requires the enterprises to possess a group of personnel grasping product process, technology and the concept, or else the enterprises cannot independently bear the implementation of waste minimization program. However, the quality of the personnel engaged in agricultural production is quite low and their thoughts are conservative. In addition, the techniques and equipments adopted by many enterprises are relatively backward. In order to change this situation, there are two problems, the first is funding constrains. It is difficult to introduce the leading technology and equipment from other countries; the second is weak technical strength. It needs a process to let the majority of farmers to fully grasp the corresponding technology.

\subsection{Information asymmetry.}

The phenomenon of information asymmetry exists in agricultural cleaner production. The direct consequence is to cause the clean agricultural product supply and demand short, reduce the allocative efficiency of agricultural resources, damage the social welfare, and affect agricultural sustainable development. In addition, lack the ability and ways to achieve cleaner production information due to because relatively short history of agricultural cleaner production, which causes large limitation in understanding the development dynamic and the latest application achievements. Although our country has done a lot of work, the process of agricultural cleaner production is still very slow.

\section{The countermeasures of developing agricultural cleaner production}

\subsection{Strengthen the consciousness of the public and construct the legal system of agricultural cleaner production.}

Through the publicity and education, make the public establish the consciousness of agricultural production, grasp the related regulations, knowledge, technology and skills, and try to fulfill in practice. Establish and perfect the legal system of agricultural cleaner production, including the standards and methods of the rural environment protection, soil pollution prevention, livestock and aquaculture environment management, and agriculture environment monitoring. And make the law and regulations coordinated and unified in content, support each other in program, to truly play the effectiveness of legal force and prevent the pollution of planting, breeding and rural industry.

\subsection{Construct technology system of agricultural cleaner production.}

Carry out systematically theoretical research to establish ecological engineering technology, green energy developing technology, the natural environment control technology, comprehensive prevention and control technology, and other agricultural cleaner production. Promote the technology of saving fertilizer, pesticide and water, and develop ecological animal husbandry, to provide technical support system for agricultural cleaner production.

\subsection{Solve the problem of asymmetric information of agricultural cleaner production.}

The government won't take the supervision and punishment mechanism to intervene agricultural cleaner production, but only encourage or stimulate and improve the competition environment of agricultural production market. In order to encourage the implementation of agricultural cleaner production, the government should formulate a series of preferential policies, such as tax relief, preferential credit, price subsides, etc. in addition, the government should also continue to vigorously improve the transportation, information and communication infrastructure, and establish and perfect the multi input system. Information asymmetry is not entirely a bad thing. It can encourage agricultural producers or sellers to provide high-quality clean production, and help consumers to distinguish the quality of agricultural products.

\section{Summary}

Agricultural cleaner production is an inevitable trend of modern agricultural development, and the important content of the sustainable development of agriculture in the future. We should strengthen the consciousness of the public and construct the legal system of agricultural cleaner production, construct technology system of agricultural cleaner production, solve the problem of asymmetric 
information of agricultural cleaner production, to promote the agricultural cleaner production successfully.

\section{References}

[1]Zixia Chai, Yongping Jin, Jinhong Chen. Discussion on agricultural cleaner production environment management system.Environment pollution and prevention, 2008,30(6):83-84,95.

[2]UJISHIM A, HONDAK. Electro-chemical photo catalysis of water at a semi-conductor electrode. Nature, 1972, 238:37-38.

[3]Farm Security and Rural Investment Act (Farm Bill), United States Department of Agriculture, Natural resources Conservation Service, Washing-ton D1C12002.

[4]Yong Wang, Changnan Zhang, Yang Chen. Discussion on agricultural cleaner production. Liaoning urban and rural environment science and technology, 2007(4): 50-53. 